\title{
KRITIK AL-GHAZĀLĪ TERHADAP PARA FILOSOF
}

\author{
Ghazali Munir \\ Institut Agama Islam Negeri (IAIN) Walisongo Semarang \\ e-mail: ghazalimunir@walisongo.ac.id
}

\begin{abstract}
Ghazālī called Bahr al-Mughriq (an ocean away) because he mastered various sciences: Fiqh , Ușūl , Mantiq and Theology. The number of contradictory religious beliefs, and the influence of Greek philosophy, arose doubt about what is right and what is wrong. Then he learned all the knowledge to get IIm Yaqin can clearly reveal the knowledge of the mutakallimun, Shiite Batinites ( Isma'ilism ), philosopher and sufism, so he left his carrier. He did not accept simply of religious truth, without knowing the reason. He divided the philosopher into three: alDahriyūn (materialists), al-Tabi'iyūn (naturalists), Ilāhiyūn (Theists). In philosophy, there are 20 issues, 3 of those mark philosophers as unbelievers, and other is bidah. Three of those are: the world eternity, unknowable particulars of God, and no physical resurrection.
\end{abstract}

\begin{abstract}
Abstrak: al-Ghazālī, seorang ulama yang menguasai berbagai ilmu pengetahuan: Fiqh, Ushul, Mantiq (Logika) dan Ilmu Kalam, sehingga ia memperoleh sebutan Bahrul Mughriq (lautan yang menenggelamkan). Banyaknya aliran keagamaan yang sering bertentangan dan pengaruh filsafat Yunani ke dalam pemikiran umat Islam, sehingga menimbulkan syak (kebimbangan, keraguan) tentang mana yang benar dan mana yang salah. Kemudian ia mempelajari seluruh ilmu untuk mendapatkan 'Ilmu Yaqin yang dapat mengungkap secara jelas yaitu ilmunya para mutakallimun, Syi'ah Batiniyah (Isma'iliyah), filosof dan sufi, sehingga ia meninggalkan jabatan dan kedudukannya. Ia tidak bertaklid tanpa mengetahui alasannya. Filosof ada tiga macam: al- Dahriyūn (materialis), al-Tabi'iyūn (naturalis) dan Ilāhiyūn (theis). Dalam filsafat terdapat 20 persoalan, 3 diantaranya menjadikan filosof kafir, dan lainnya bid'ah. Tiga (3) itu adalah: Pendapat tentang
\end{abstract}


GHAZALI MUNIR:Kritik al-Ghazālī terhadap Para Filosof

keazalian alam, pendapat bahwa Tuhan tidak mengetahui juz'iyyat (rinci), dan kebangkitan jasmani tidak ada.

Keywords: syak, 'ilm al-yaqīn, al-Dahriyūn, alṬabi'iyūn, Ilāhiyūn

\section{A. Pendahuluan}

Al-Ghazālī, yang nama lengkapnya adalah AbūḤāmid Muḥammad bin Muhammad al-Ghazālī, dilahirkan di Ṭūṣ, sebuah kota di Khurasan (dekat Masyhad sekarang), Persia, pada tahun 450 H/1058 M. Dia mempunyai seorang saudara laki-laki bernama Ahmad yang tercatat sebagai sufi dan menulis buku dalam bahasa Persia. Ayahnya adalah seorang penenun bulu (ghazzāl) yang miskin. Menjelang akhir hayatnya, dia menitipkan kedua anaknya itu kepada salah seorang sufi teman karibnya, dengan pesan agar keduanya dididik dengan baik sampai harta peninggalannya habis. Pesan tersebut dilaksanakannya dan setelah harta itu habis, mereka disarankan agar tetap menuntut ilmu sedapat-dapatnya. ${ }^{1}$

Mengenai riwayat pendidikan al-Ghazālī ini secara singkat dapat dikemukakan sebagai berikut. Mula-mula dia belajar kepada Aḥmad bin Muhammad al-Razikani di Ṭūṣ, kemudian merantau ke Jurjan, di Tenggara Laut Kaspia, untuk melanjutkan belajar kepada Abū Nāṣr al-Ismā'īl. Setelah itu dia kembali lagi ke Ṭūṣ sebelum berhijrah ke Naisapur, pada sekitar tahun 1077, untuk mempelajari Fiqh, Ușūl, Mantiq (Logika) dan Ilmu Kalam kepada Diyā' al-Dīn alJuwainī, kepada Madrasah Niẓamiyah pada waktu itu, yang juga dikenal sebagai Imām al-Harāmain.Dia belajar kepadanya sampai beliau wafat pada tahun $478 \mathrm{H} / 1085 \mathrm{M}$, dan daripadanya dia memperoleh gelar Bahr al-Mughriq (laut yang menenggelamkan) sebagai penghargaan atas kecerdasan otaknya dan kepandaiannya berdiskusi. $^{2}$

Tentang al-Juwainī, guru al-Ghazālī, ini dapat dijelaskan bahwa dia adalah tokoh Asy'ariyah di Naisapur yang terpaksa mengungsi ke 
Mekkah dan Madinah karena aliran yang dianutnya, semenjak tahun 1053, dimusuhi oleh al-Kundurī, wazir Tughril Bek yang berkuasa pada waktu itu. Dan setelah Tughril Bek ini meninggal, dan digantikan oleh Alp Arsalan, al-Kundurī juga diganti oleh Niẓām alMulk yang menganut mazhab teologi Asy'ariyah dan mazhab Fiqh Syāfi'î.Pada saat itulah al-Juwainī kembali dari Mekkah dan Madinah, dan karena itu pula, dia dikenal sebagai Imām al-Harāmain. ${ }^{3}$ Dari sini jelas bahwa untuk pertama kalinya al-Ghazālī mengenal mazhab teologi Asy'ariyah dan mazhab Fiqh Syāfi'î dari al-Juwainī ini.

Sepeninggal gurunya yang terakhir ini, al-Ghazālī berhijrah ke al-Mu'askar, sampai akhirnya menjadi guru pada Madrasah Nizamiyyah di Baghdad selama empat tahun (484 H/1091 M - 488 H/1095 M). Sambil mengajar, al-Ghazālī mulai menulis buku-buku, diantaranya adalah: al-Basiț, al-Wasiț, al-Wajīz, al-Khulāṣah fi al-'Ilm al-Fiqh, al-Munqīl fi 'Ilm al-Jidāl, Ma'khad al-Khilāf, Lubāb al-Naẓar, Tahsīn al-Ma'akhiz, dan al-Mabādi' wal Ghayah fi Fann al-Khilāf.

Satu hal yang barangkali istimewa dalam karir intelektual alGhazālī ini adalah bahwa pada saat yang sama dia mampu mempelajari sendiri dan menguasai filsafat al-Farābī dan Ibn Sīnā suatu prestasi yang belum pernah dicapai oleh teolog manapun pada saat itu-, Maqāṣid al-Falāsifah, yang sejak abad pertengahan telah diterjemahkan ke dalam bahasa Latin dan juga sangat berpengaruh. Kemudian dia menulis kritik terhadap pemikiran-pemikiran filosofik mereka dalam buku lainnya, Taḥāfut al-Falāsifah. ${ }^{5}$ Sanggahansanggahan dan kritik-kritiknya inilah yang pada dasarnya merupakan pokok bahasan dalam makalah ini.

Sebelum membahas kritik-kritik tersebut barangkali ada baiknya ditinjau lebih dahulu motivasi al-Ghazālī mempelajari filsafat dan merangkumnya dalam buku Maqāṣid al-Falāsifah, setidaktidaknya untuk lebih memahami latar belakang karir intelektualnya. 


\section{B. Al-Ghazālī dan 'Ilm al-Yaqīn}

Salah satu fakta yang barangkali dapat membantu menjelaskan hal ini adalah, bahwa pada masa hayat al-Ghazāli terdapat berbagai macam aliran atau mazhab keagamaan yang selain berlawanan satu sama lain juga masing-masing menganggap dirinya benar. Selain itu, pada saat itu juga sangat terasa pengaruh pemikiran filsafat Yunani yang masuk ke dalam alam pikiran umat Muslim semenjak masa Mu'tazilah sampai dengan munculnya filosof-filosof al-Farābī, alKindī dan Ibn Sīnā. Bagi al-Ghazālī kenyataan tersebut selain menimbulkan syak atau keragu-raguan mengenai manakah yang benar dan mana pula yang salah, juga mendorongnya untuk mempelajari seluruhnya, sehingga pada akhirnya diharapkan dapat ditemukan apa yang disebutnya 'ilm al-yaqīn, yaitu ilmu pengetahuan yang betul-betul bisa mengungkapkan permasalahan dengan jelas tanpa keraguan, kesalahan maupun kebimbangan sedikitpun.

Dalam bukunya, al-Munqiz min al-p̣alāl, al-Ghazālī secara eksplisit menegaskan:

$$
\begin{aligned}
& \text { أن العلم اليقيني هو الذي ينكشف فيه المعلوم انكشافاً لا يبقى معه ريب، ولا يفارقه إمكان الغلط }
\end{aligned}
$$

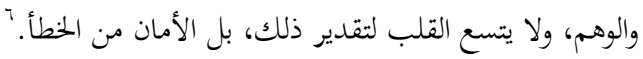

Penyakit syak yang selama beberapa bulan diderita oleh alGhazālī, di samping keinginannya untuk mendapatkan 'ilm al-yaqīn, itulah yang antara lain mendorongnya untuk meninggalkan semua jabatannya yang relatif sangat menguntungkan itu. Dia tinggalkan karirnya sebagai ahli hukum (fäqih), teolog (mutakallimin) dan guru di Madrasah Nizamiyah agar dapat mengabdi kepada Allah secara lebih sempurna sebagai seorang sufi. ${ }^{7}$

Yang menjadi pertanyaan adalah, apakah hal itu merupakan satu-satunya alasan atau penyebab baginya untuk meninggalkan Baghdad, dan menanggalkan semua jabatan dan posisinya, ataukah ada alasan atau penyebab lain. al-Ghazālīsendiri, dalam bukunya alMunqiz min al-Dalāl itu, secara eksplisit memang hanya 
menyebutkan alasan tersebut. Tetapi bila dikaitkan dengan situasi sosial-politik yang ada pada saat itu (sekitar tahun 1090-an), tidak mustahil adanya alasan lain.

Dalam hubungan ini, Watt mengemukakan dua fakta lain yang mungkin ikut mendorong al-Ghazālī meninggalkan Baghdad dan menanggalkan semua jabatan dan kedudukannya, yaitu: (1) yang bersifat politik, bahwa al-Ghazālī tidak menyetujui kebijakan politik Sultan Barkiyaruk dari Bani Saljuk untuk berperang fisabīl Allāh melawan pasukan Salib, dan (2) yang bersifat sosio-religius, bahwa al-Ghazālī muak dengan sikap rekan-rekannya (para ahli hukum dan pemikir Muslim) yang cendrung terlalu duniawi.8Bahkan menurut Watt, fakta kedua inilah yang merupakan alasan utama baginya untuk meninggalkan karirnya karena dia merasa tidak mungkin menegakkan kehidupan yang lurus dalam lingkungan semacam itu. ${ }^{9}$ Dengan memperhatikan bahwa setelah terjadi pergantian kekuasaan dalam dinasti Bani Saljuk ke tangan salah seorang putera Nizām alMulk di tahun 1104, ternyata al-Ghazālī bersedia kembali menjadi guru di Naisapur pada saat-saat terakhir menjelang wafatnya, yaitu pada tahun 1106-1109.10Dengan demikian, kedua alasan yang dikemukakan oleh Watt ada juga kebenarannya.

Hal lain yang perlu dikemukakan dalam hubungan ini adalah bahwa al-Ghazālī dalam bukunya al-Munqiz min al-Dalāl menyatakan telah sembuh dari penyakit syak atau keraguannya atas pertolongan Allah. Dan dia menyatakan bahwa untuk mendapatkan apa yang disebutnya 'ilm al-yaqin itu dia menyebut empat kelompok yang harus dipelajarinya, yaitu: mutakallimūn, kelompok batiniyah (Syi'ah Isma'iliyah), para filosof, dan para ahli sufi. ${ }^{11}$

Dari uraian di atas jelas bahwa minat al-Ghazālī untuk mempelajari keempat kelompok tersebut didorong oleh keinginannya untuk mendapatkan apa yang disebutnya 'ilm al-yaqīn itu. Dan alasan itu pulalah, di samping dua alasan lain yang bersifat sosio- 
GHAZALI MUNIR:Kritik al-Ghazālī terhadap Para Filosof

politik dan sosio-religius, yang mendorongnya meninggalkan Baghdad dan menanggalkan semua jabatan serta kedudukannya.

\section{C. al-Ghazālī tentang Filsafat}

Salah satu keistimewaan al-Ghazālī dalam karir intelektualnya adalah bahwa dia tidak mau bertaklid atau mengikuti pendapat orang lain begitu saja, tanpa mengetahui alasan-alasannya secara seksama. Karena itu sebagaimana dikemukakan dalam bukunya, alMunqiz min al-Dalāl, dia berusaha memahami secara tuntas semua bidang yang dikajinya, termasuk di dalamnya mengenai filsafat ini. ${ }^{12}$

Menurut hasil penelaahannya, para filosof dapat dikelompokkan menjadi tiga: (1) al-dahriyūn (2) al-țabi'iyūn, dan (3) ilāhiyūn. Al-Dahriyūn adalah kelompok filosof yang tidak percaya akan adanya Pencipta Alam dan beranggapan bahwa alam itu terjadi dengan sendirinya tanpa pencipta. Mereka adalah orang-orang kafir zindiq. ${ }^{13} \mathrm{Al}$-Tabi'iyūn adalah kelompok filosof yang banyak membicarakan alam benda tetapi mengingkari hari kiamat, surga, neraka dan perhitungan (hisāb); dan mereka juga termasuk orang-orang kafir zindiq. ${ }^{14}$ Sedangkan Ilāhiyūn adalah kelompok filosof yang bertentangan dengan kelompok pertama, dan termasuk di antaranya adalah Socrates, Plato, dan Aristoteles serta penganut-penganutnya dari kalangan Muslim seperti Ibn Sīnā, al-Farābī dan lain-lainnya. ${ }^{15}$

Sedangkan rincian Ilmu Filsafat itu sendiri al-Ghazālī mengelompokannya menjadi 6 bagian: (1) matematika, (2) logika, (3) fisika, (4) metafisika, (5) politik, dan (6) etika. Di antara keenam bidang tersebut, menurut al-Ghazālī, yang paling banyak kemungkinan salahnya adalah ilmu metafisika; karena itu perlu ada ketelitian dalam menilai ilmu ini. Al-Ghazālī menyebut 20 masalah metafisika, yang juga disebutnya secara panjang lebar dalam bukunya Taḥāfut al-Falāsifah, tiga di antaranya menyebabkan orang menjadi kafir dan 17 lainnya menyebabkan orang bidah. ${ }^{16}$ Ketiga masalah yang menyebabkan kafir itu adalah: 
1. Pernyataan mereka bahwa kebangkitan jasad tidak ada; yang ada hanyalah kebangkitan ruhani, dan ruhani itu pulalah yang kelak diberi pahala atau disiksa.

2. Pengingkaran mereka terhadap Syari'ah yang menyatakan bahwa Allah mengetahui yang kulliyat dan juz'iyat; mereka hanya mengakui pengetahuan Allah tentang yang kulliyat saja, dan

3. Pernyataan mereka tentang nafy al-șifat dan bahwa Allah mengetahui tidak dengan ilmu yang melekat pada zat-Nya sebagaimana dianut oleh mazhab Mu'tazilah. ${ }^{17}$

Dari uraian ini jelaslah bahwa tidak semua cabang ilmu filsafat dikritik oleh al-Ghazālī, yang dikritiknya hanyalah pada cabang metafisikanya. Dalam kaitan ini perlu dikemukakan bahwa alGhazālī, sebagai sufi, cenderung menilai segala ilmu pengetahuan, termasuk filsafat, sesuai dengan manfaat dan madaratnya bagi orang yang mengkajinya. Karena itu sebagaimana dikemukakan dalam bukunya, Ihyyā' 'Ulūm al-Dīn, dia mengklasifikasikan ilmu pengetahuan ke dalam apa yang disebut ilmu pengetahuan tercela, ilmu pengetahuan yang terpuji, dan ilmu pengetahuan yang terpuji sampai tingkat tertentu dan tercela bila didalami lebih lanjut. ${ }^{18}$

Untuk mengetahui posisi filsafat dalam pemikiran al-Ghazālī, barangkali ada baiknya dikemukakan di sini klasifikasi ilmu pengetahuan menurut pandangannya.Secara garis besar al-Ghazālī mengelompokkan ilmu pengetahuan ke dalam Ilmu-ilmu Syar'iyah dan Ilmu-ilmu Ghairu Syar'iyah. Secara ilmu Syar'iyyah termasuk terpuji (mahmmūdah) dan ia terdiri dari: (1) Ilmu-ilmu Ușul; (a) alQur'an, (b) Sunnah Rasul, (c) Ijma' Ulama, dan (d) Aśar Sahabat; (2) Ilmu-ilmu Furu', misalnya Fikih; (3) Ilmu-ilmu mutammimat, yaitu yang berhubungan dengan Ilmu al-Qur'an. Sedangkan Ilmu-ilmu Ghairu Syar'iyah, menurut al-Ghazālī, terdiri dari (1) ilmu-ilmu mạ̣mūdah (terpuji), yaitu ilmu-ilmu yang dibutuhkan dalam 
GHAZALI MUNIR:Kritik al-Ghazālī terhadap Para Filosof

kehidupan dan penghidupan serta pergaulan manusia, misalnya kedokteran, ilmu hitung dan teknologi; (2) ilmu-ilmu mażmūmah (tercela), yaitu ilmu-ilmu yang membahayakan pemiliknya atau orang lain, jika dipelajari dan ditekuni, seperti ilmu sihir, astrologi dan beberapa cabang filsafat. ${ }^{19}$

Mengenai filsafat ini, al-Ghazālī memberikan penilaian sebagai berikut:

1. Ilmu Pasti termasuk ilmu mubah, tetapi kadang-kadang berbahaya karena murid akan terpengaruh oleh ketelitian bukti-buktinya dan kagum akan hakikatnya, sehingga dia akan mengagumi juga filsafat dan aneka pemikiran dalam cabangcabang filsafat, seperti teologi, yang menurut al-Ghazālī merupakan ilmu terlarang.

2. Logika (Mantiq), meskipun termasuk ilmu mubah kadangkadang juga berbahaya sebagaimana ilmu pasti atau matematika. Ia tidak ada hubungannya dengan agama.

3. Teologi (Ilmu Kalam), yang mempelajari zat Allah SWT, banyak mengandung kesalahan para filosof sehingga ada yang sampai taraf kufur dan ada yang bid'ah. Karena itu anak kecil atau orang yang belum kuat dikhawatirkan menjadi kufur atau terus menerus melakukan bid'ah.

4. Ilmu Alam (Fisika), terutama aliran naturalismenya dapat mengakibatkan orang mengingkari adanya ruh atau berpendapat bahwa ruh itu akan rusak. Jadi di sini ada bahayanya juga.

5. Politik dan 6. Etika, menurut al-Ghazālī bersumber pada alQur'an, hikmah para nabi, para wali dan sufi. Tetapi dalam hal ini para filosof menambahkan pendapat-pendapatnya sendiri sehingga timbul dua kemungkinan: (1) ditolak karena menolak firman Allah atau (2) diterima karena dianggap bersumber dari hikmah para nabi dan para wali. ${ }^{20}$ 
Dari sini dapat ditarik kesimpulan bahwa pada dasarnya alGhazālī menempatkan semua ilmu Ghairu Syar'iyah dibawah otoritas wahyu atau dibawah ilmu-ilmu Syar'iyah. Karena itu, kritik alGhazālīterhadap para filosof seperti akan diungkapkan lebih lanjut harus diletakkan pada kerangka pemikirannya itu.

\section{Kritik terhadap Para Filosof}

Seperti sudah dikemukakan sebelumnya bahwa kritik alGhazālī terhadap para filosof terdiri dari atau menyangkut 20 permasalahan. Secara rinci ke-20 masalah tersebut adalah sebagai berikut:

1. Pendapat tentang keazalian atau ke-qudūm-an alam. ${ }^{21}$

2. Pendapat tentang kekekalan alam. ${ }^{22}$

3. Kerancuan pemikiran tentang Allah sebagai pencipta alam dan alam sebagai ciptaan-Nya. ${ }^{23}$

4. Ketidakmampuan mereka untuk membuktikan adanya pencipta alam. ${ }^{24}$

5. Ketidakmampuan mereka untuk menunjukkan ketidakmungkinan adanya dua tuhan. ${ }^{25}$

6. Pendapat mereka tentang peniadaan sifat Allah. ${ }^{26}$

7. Pendapat tentang Zat Pertama (Tuhan) yang tidak dapat dibagi menjadi jins(jenis) dan faṣl (diferensia). ${ }^{27}$

8. Pendapat tentang Tuhan yang tidak memiliki māhiyah (hakekat). ${ }^{28}$

9. Ketidakmampuan mereka untuk menjelaskan bahwa Tuhan tidak memiliki tubuh (jism). ${ }^{29}$

10. Ketidakmampuan mereka membuktikan bahwa alam mempunyai pencipta. ${ }^{30}$

11. Ketidakmampuan mereka membuktikan bahwa Tuhan mengetahui yang ada di luar diri-Nya. ${ }^{31}$ 
GHAZALI MUNIR:Kritik al-Ghazālī terhadap Para Filosof

12. Ketidakmampuan mereka membuktikan bahwa Tuhan mengetahui esensi-Nya sendiri. ${ }^{32}$

13. Pendapat mereka bahwa Tuhan tidak mengetahui yang rinci (juz'iyat). ${ }^{33}$

14. Pendapat mereka bahwa langit adalah bintang yang bergerak dengan kemauan. ${ }^{34}$

15. Pendapat mereka tentang adanya tujuan yang menggerakkan langit. 35

16. Pendapat mereka bahwa jiwa-jiwa langit mengetahui semua juz'iyat. ${ }^{36}$

17. Pendapat mereka tentang ketidakmungkinan terjadinya peristiwa yang luar biasa. ${ }^{37}$

18. Pendapat mereka bahwa jiwa manusia merupakan substansi yang terdiri sendiri, bukan jism bukan 'ard (accident). ${ }^{38}$

19. Pendapat mereka tentang ketidakmungkinan hancurnya jiwajiwa manusia, ${ }^{39}$ dan

20. Pendapat mereka tentang tidak adanya kebangkitan jasmani, beserta kesenangan dan kesengsaraan di surga dan neraka dengan kesenangan dan siksa jasmaniah. ${ }^{40}$

Seperti sudah dikemukakan sebelumnya bahwa 17 masalah diantaranya dapat menyebabkan orang menjadi mubtadi' (melakukan bidah), sedangkan 3 masalah lainnya dapat menyebabkan orang menjadi kafir. Yang disebut belakangan adalah:

1. Pendapat (masalah ke-1) tentang keazalian atau ke-qudūm-an alam;

2. Pendapat (masalah ke-13) bahwa Tuhan tidak mengetahui yang rinci (juz'iyat);

3. Pendapat (masalah ke-20) tentang tidak adanya kebangkitan jasmani. ${ }^{41}$ 
Sedangkan pendapat-pendapat lainnya, menurut al-Ghazālī, ada kemiripannya dengan mazhab Mu'tazilah tetapi dia tidak berani mengkafirkannya, melainkan hanya menyebut ahl al-bida', ${ }^{\prime 2}$

Dengan demikian sebenarnya sasaran utama kritik al-Ghazālī bukanlah filsafat secara in toto, melainkan beberapa aspek saja dari cabang filsafat, yaitu metafisika, yang dianggapnya berlawanan sama sekali dengan Islam. Walaupun kritiknya ini bisa dikatakan sangat keras, ternyata ia tidak menghambat perkembang filsafat Islam pada masa-masa sesudahnya, kecuali di kalangan sebagian kecil umat Muslim Sunni. Henri Corbin dari Prancis dalam bukunya Histoire de la Philosophie Islamique, sebagaimana dikutip oleh Harun Nasution, menyatakan bahwa "salahlah pendapat yang mengatakan bahwa falsafah sesudah al-Ghazālī, berpindah ke dunia Islam bagian Barat; demikian pula salah pendapat yang mengatakan bahwa filsafat tidak bangkit sesudah mendapat pukulan dari al-Ghazālī.Dia tetap tinggal di dunia Islam bagian Timur, dan demikian kecil pengaruh pukulan itu sehingga masih terdapat pengikut-pengikut Ibn Sīnā sampai hari ini.Karya-karya besar yang dihasilkan sekolah Isfahan menjadi buktinya". 43

\section{E. Komentar}

Bila diperhatikan argumen-argumen al-Ghazālī dalam bukunya Tahāfut al-Falāsifah, boleh dikatakan bahwa dia menggunakan logika untuk mengkritik para filosof.Namun dibalik itu secara implisit tercermin sikap teologinya sebagai penganut aliran Asy'ariyah.Hal ini terlihat misalnya dalam penolakannya terhadap pandangan para filosof mengenai keqadiman alam.Baginya yang qadim hanyalah Allah dan sifat-sifat-Nya.Karena alam bukan sifat Allah, dan dia juga menolak bahwa alam merupakan limpahan Allah, berarti alam itu tidak qadìm melainkan hadišs.Ia tidak lebih daripada ciptaan Allah. Hal lain yang menunjukkan keterikatannya dengan aliran Asy'ariyah adalah penolakannya terhadap nafy al-sifat, yang diyakini oleh mazhab Mu'tazilah. Dengan perkataan lain bahwa dalam hal ini, 
secara implisit bahkan eksplisit, al-Ghazālī menolak aliran NeoPlatonisme dan Mu'tazilah. Dan ini bisa dimaklumi karena dia hidup pada masa pasca Abbasiyah, pada saat itu Mu'tazilah telah mengalami kemunduran.

Mengenai penolakannya terhadap pendapat-pendapat para filosof bahwa Allah tidak mengetahui juz'iyat dan bahwa tidak ada kebangkitan jasmani, kiranya dapat dipahami karena memang bertentangan dengan banyak ayat al-Qur'an.beberapa di antaranya dapat disebutkan sebagai berikut:

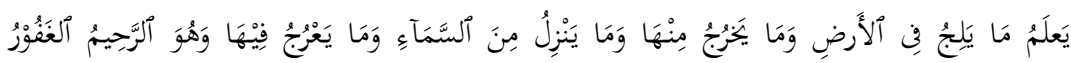

$$
\begin{aligned}
& \text { (السبأ:r) }
\end{aligned}
$$

Dia mengetahui apa yang masuk ke dalam bumi, apa yang ke luar daripadanya, apa yang turun dari langit dan apa yang naik kepadanya. dan Dia-lah yang Maha Penyayang lagi Maha Pengampun.

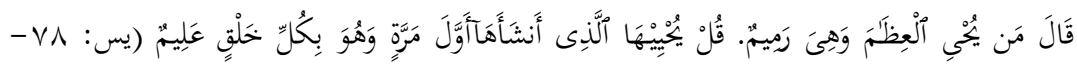

Dan ia membuat perumpamaan bagi kami; dan Dia lupa kepada kejadiannya; ia berkata: "Siapakah yang dapat menghidupkan tulang belulang, yang telah hancur luluh?" Katakanlah: "Ia akan dihidupkan oleh Tuhan yang menciptakannya kali yang pertama. Dan Dia Maha mengetahui tentang segala makhluk".

\section{F. Penutup}

Tanpa mengurangi rasa hormat kepada al-Ghazālī, sebenarnya dapat dikatakan bahwa kritik-kritiknya terhadap para filosof bukan tanpa kelemahan; apalagi jika dikaitkan dengan tanggapan Ibnu Rusyd dalam bukunya Taḥāfut al-Taḥāfut. Namun demikian, kritikkritiknya tersebut merupakan salah satu keberhasilan al-Ghazāli dalam meletakkan dasar-dasar bagi sikap Muslim Sunni terhadap filsafat, di samping keberhasilan-keberhasilan lainnya dalam 
menghadapi kelompok Syi'ah Isma'iliyah serta menghidupkan tradisi Sufi dalam masyarakat Muslim Sunni. ${ }^{44}$ Bagaimanapun juga dia adalah tokoh pembaharu pada masanya dengan sekian banyak peninggalan karya tulisnya, yang tidak kecil artinya bagi generasi Muslim sesudahnya. []

\section{Catatan Akhir}

${ }^{1}$ Fathiyah Hasan Sulaiman, Konsep Pendidikan al-Ghazali, terj. Ahmad Hakim dan M. Imam Aziz, Jakarta: P3M, 1986, h. 6; W. Montgomery Watt, Pemikiran Teologi dan Filsafat Islam, terj. Umar Basalim, Jakarta: P3M, 1987, h. 138-139; dan Sulaimān Dunyā, "Ijmāl 'an Ḥayāti al-Ghazālī al-Fikriyah", dalam al-Ghazālī, Taḥāfut alFalāsifah, disunting oleh Sulaimān Dunyā, Qāhirah: Dār al-Ma'ārif bi Mișra, 1966, h. 49.

2Fathiyah Hasan Sulaiman, Konsep, h. 7-8; H.A.R. Gibb \& J.H. Kraemers, Shorter Encyclopedia of Islam, Leiden: E.J. Brill, 1953, h. 111; dan W. Montgomery Watt, The Majesty that Was Islam, The Islamic World, 661-1100, London: Sedgwick \& Jackson, 1974, h. 251-252.

3 W. Montgomery Watt, The Majesty, h. 251-252.

4Fathiyah Hasan Sulaiman, Konsep, h. 8.

5W. Montgomery Watt, Pemikiran Teologi, h. 139.

6al-Ghazālī, al-Munqiz min al-Ḍalāl, Fatih, Istanbul: Hakikat Kitabevi, 1981, h. 4.

7W. Montgomery Watt, Pemikiran Teologi, h. 140.

8Ibid.; juga W. Montgomery Watt, The Majesty, h. 248 dan 253.

${ }^{9}$ W. Montgomery Watt, Pemikiran Teologi, h. 140.

${ }^{10}$ Ibid., h. 141.

${ }^{11}$ Al-Ghazali, al-Munqiz, h. 8.

12Ibid., h. 3

13Ibid., h. 11.

${ }^{14}$ Ibid.

15Ibid., h. 13.

16Ibid., h. 16.

17Ibid., h. 16-17.

18Fathiyah Hasan Sulaiman, Konsep, h. 23.

19Ibid., h. 27-30. 
20Ibid., h. 30-32.

21al-Ghazālī, Tahafut, h. 77-123.

22Ibid., h. 124-133.

23Ibid., h. 134-154.

24Ibid., h. 155-159.

25Ibid., h. 160-171.

26Ibid., h. 172-183.

27Ibid., h. 184-189.

28Ibid., h. 190-192.

29Ibid., h. 193-195.

30Ibid., h. 196-197.

31Ibid., h. 197-202.

32Ibid., h. 203-205.

33Ibid., h. 206-217.

34Ibid., h. 218-221.

35Ibid., h. 222-225.

36Ibid., h. 226-233.

${ }^{37}$ Ibid., h. 239-245.

38Ibid., h. 252-273.

39Ibid., h. 274-281.

40Ibid., h. 282-306.

41Ibid., h. 307-309.

42Ibid., h. 309.

43Harun Nasution, "al-Ghazali dan Filsafat", makalah dalam Simposium tentang al-Ghazali di Jakarta, 26 Januari 1985, h. 9.

${ }^{44} \mathrm{~W}$. Montgomery Watt, The Majesty, h. 253. 


\section{DAFTAR PUSTAKA}

Ahwani, Ahmad Fuad, Filsafat Islam, terj. Pustakan Firdaus, Jakarta: Pustaka Firdaus, 1988.

Al-Ghazālī, Maqāṣid al-Falāsifah, disunting oleh Sulaimān Dunyā, Qāhirah: Dār al Ma'ārif bi Miṣra, 1960.

Boer, T.J. De, The History of Philosophy in Islam, New York: Dover Publications Inc., 1967.

Daud Remantan, et.al.,Pengantar Filsafat Islam, Banda Aceh: IAIN Jami'ah ar-Raniry, 1982/1983.

Fakhry, Majid, A History of Islamic Philosophy, New York \& London: Columbia University Press \& Longman, 1983.

Galab, Muhammad, al-Ma'rifah 'Inda Mufakkir al-Muslimīn, al-Fajalah: Dār al-Mișriyah li al-Ta'lif wa al-Tarjamah, t.t.

Ghazālī, al-Munqiz min al-Ḍalāl, Fatih, Istanbul: Hakikat Kitabevi, 1981.

Ghazālī, Tahatufut al-Falāsifah, disunting oleh disunting oleh Sulaimān Dunyā, Qāhirah: Dār al Ma'ārif bi Miṣra, 1966.

Gib, H.A.R., \& J.H. Kraemers, Shorter Encyclopedia of Islam, Leiden: E.J. Brill, 1953.

McDonald, Duncan B, Development of Muslim Theology, Jurisprudence and Constitutional Theory, New York: Charles Scribner's Sons, 1970.

Nasr, Seyyed Hossein, Islamic Life and Thought, Albany: State University of New York Press, 1981.

Nasr, Seyyed Hossein, Science and Civilization in Islam, New York: New American Library, 1970.

Simposium tentang al-Ghazali, Kumpulan Makalah, Jakarta: Badan Kerjasama Perguruan Tinggi Islam Swasta, 1985. 
Sulaiman, Fathiyah Hasan, Konsep Pendidikan al-Ghazali, terj. Ahmad Hakim dan M. Imam Aziz, Jakarta: P3M, 1986.

Watt, W. Montgomery, Pemikiran Teologi dan Filsafat Islam, terj. Umar Basalim, Jakarta: P3M, 1987.

Watt, W. Montgomery, The Majesty that Was Islam, The Islamic World, 661-1100, London: Sedgwick \& Jackson, 1974. 